\title{
Emotional Work in Preschool Teacher's Everyday Lives: A Theoretical Outline and Dialogue with Critical Pedagogy
}

\author{
Yin-Kun Chang \\ Institute of Early Childhood Education, National Cheng-Chi University, Taiwan
}

Copyright $\bigcirc 2016$ by authors, all rights reserved. Authors agree that this article remains permanently open access under the terms of the Creative Commons Attribution License 4.0 International License.

\begin{abstract}
This paper points out educational study is not only a pure macro-oriented focus such as analysis for policy and ideological formation; rather, it also must be in synchronicity with the actual socio-historical process and the baseline of everyday life in the micro level. Thus, this paper considers that emotional issues may be the good windows to inquire schoolteachers' everyday lives. First, this paper reviews relevant theories in multiple disciplines to systematically politicize emotions as an important site of educational research. Second, this paper emphasizes that to understand emotions are inscribed in culture and ideology, as "embodied and situated." Finally, this paper's focus is not only on how social factors affect what schoolteacher feel, but also on how schoolteachers mobilize their feeling to creation a condition for social transformation. That is, the ultimate purpose is to answer "can one explain the possibility of resistance from an oppressed position through emotion mobilization?" and to build up this model-the emotional requirement for subversive action: "structure of feeling" is an important social condition for intervention from anger to joyful/hopeful commitment to social transformation.
\end{abstract}

Keywords Emotion Politics, Critical Pedagogy

Being able to dance with the feet, with concepts, with words: do I still have to say that one has to be able to dance with the pen (Niethzsche, 1968: 68).

\section{Introduction: Emotion as Microanalysis for Teachers' Everyday Lives}

There is not difficult to feel this dilemma: on the one hand, teachers are regularly maligned in public discourses of education reform; and on the other hand, many teachers' narratives such as action research or autobiography appeal against their oppressed lives in this situation. In my eyes, this is an interesting fact already discussed in many papers. In general, we can get a clear picture that many teachers do not really welcome educational reform and they feel it will weight their teaching loads. They get used to teaching with textbooks in the traditional way, instead of designing curricula and preparing extra instructional materials by themselves, because it will occupy their time. To put it differently, some teachers also express this paradox: if they want to transform their teaching or other issues in schooling, they will suffer some trouble from colleagues such as envy and bitter language. Thus, it's crucial to focus on this contradictory emotion in the educational field: schoolteachers tend to welcome educational reform in the abstract level, but they also develop euphemistic strategies to handle with this reform at the same time. Some papers use certain narratives (like action research or autobiography) coming from schoolteachers' voices to offer deep descriptions about teachers' everyday lives. They point out that teachers were restrained by a number of rules and they cannot conduct real instruction autonomy. They just repeat their old instruction style year after year.

Although many papers already describe schoolteachers' everyday lives, I didn't find any proper work focusing on emotion issues systematically. According to my literature review, only few master theses or dissertations focus on this issue. For instance, Chien (2005) uses teachers' teaching journal writing on the Internet as an example to inquire the emotional issues of teacher-student interactions to understand how emotions influence teachers' works and their life worlds. He major finding includes: it is always with certain tensions between working in an institutionalized school and the teacher's educational ideals. This causes emotional reactions of miseries when teachers interact with their students. Negative emotional reactions also cause serious punishments and make hard memories in teachers' teaching careers. In my own interpretations, the already pressured 'self' of the teacher who receives disrespectful, 
unfair, invalidating treatment undergoes intense emotional pain. Thus, reflected time and again in descriptions of difficult and uncomfortable memories, teachers told of being "angry," "hurt," "flabbergasted," "humiliated" and "fearful" when the professional self was threatened.

As Hargreaves (1998) emphasizes, "Teaching is an emotional practice." Teaching is not just a technical practice but also an emotional one. Teaching also both expresses teachers' own feelings, and affects the feelings of others. Although emotion is an obvious topic for observation, outsider like researcher sometimes cannot figure out their emotional rule well or outsider also feels difficult to portray any detail about these rules. This is a reason why I think so highly of action research or autobiographical narratives, because in traditional academic writing, to address emotions is always insignificant matter-especially for schoolteacher's emotion already marginalized within the hierarchy of the educational research. ${ }^{1}$ In my opinion, the educational study is not only a pure macro-oriented focus such as analysis for policy and ideological formation; rather, it also must be in synchronicity with the actual socio-historical process and the baseline of everyday life in the micro level. Institutional analyses sometimes neglect the significance of action and interaction. That is, the day to day interactions and regularities from the hidden curriculum that tacitly taught important norms and values would be an important issue for research. For instance, the phenomenon of schoolteacher's emotion has begun to attract a great deal more attention from educational researchers such as critical pedagogy or feminist pedagogy in recent years. One may feel disgust, loathing, or sentimental affection. These feelings are just as important as one's beliefs in determining whether or not one consents to a given social structure or whatever.

We may say that emotional issues may be one of good windows to inquire schoolteachers' everyday lives. In particular, the emotional narratives seem like Derrida's idea "supplement" for current blank page. We should discover the uncharted territory of what teachers are really feeling. For this purpose, first I will review relevant theories in multiple disciplines to systematically theorize emotions as an important topic of educational research. Second, to understand emotions are inscribed in culture and ideology, as "embodied and situated." In educational issues, all emotionality experienced by teachers in their classrooms or schools has reference to their primary self and to their occupational selves-the current teaching self, hoped-for

\footnotetext{
${ }^{1}$ According to the social anthropologist Mary Douglas, any system of classification is an ordering, and ordering requires the rejection of "inappropriate elements" (Douglas, 1966: 35). If an order or systematic pattern is to be maintained, we have to eject or exclude that which would challenge the pattern and its continuation. Krantz (2003: 228) criticizes that social theory and research have pretty much ignored emotion. The open expression of emotion is generally discouraged in the public, particularly Habermas, the most often cited scholar on the deliberative democracy, essentially ignores the role of emotion. In the similar situation, in the mainstream educational research, emotional issue is usually ejected or excluded issue without any significant contribution.
}

teaching selves, feared teaching selves, and their "ought" and "ought-not" teaching selves (Higgins, 1987).That is, emotions signal that something important to survival or thriving is at stake. That means emotionality signals that something has transpired that is important to the individual's self, or more accurately, the individual's selves or self-system (Shweder, 1994).

How can we master the emotion deeply in schoolteachers' everyday lives? Wentworth and Ryan's (1992) idea “deep sociality" of emotion offers us a way of moving beyond micro-analytic, subjective, individualistic levels of analysis, towards more open-ended forms of social inquiry in which embodied agency can be understood not merely as meaning-making, but also as institution-making. This is because emotions are "cognitive," or "conceptual" shaped by beliefs and perceptions. What's more, I think we should divide emotion into two sections: emotion to (acts in certain ways) and emotion from (oppressive structures, practices, and modes of thoughts). My focus includes rhetorical and action dimensions to emotional awareness, expressions, attributions of meanings, and interpretations. For instance, I will also explore an "emotional rhetoric" that frequently accompanies one's talk about emotions or encounter relevant events. Finally, as I see it, the schoolteachers' narratives have become a stereotype of universal anger or mope targeting education reform. I do not believe that this stereotype is completely accurate in the real word. My focus is not only on what social factors affect schoolteachers' feelings, but also on how schoolteachers mobilize their feeling to creation a condition for social transformation. That is, my ultimate purpose is to answer "can one explain the possibility of resistance from a oppressed position through emotion mobilization?", and to build up this model-the emotional requirement for subversive action: "structure of feeling" is an important social condition for intervention from anger to joyful/hopeful commitment to social transformation.

\section{Theoretical Review}

What is the proper definition for emotion? How can we analyze emotion more culturally with different traditions? For example, Robin Collingwood (1958: 203-206) divides expressions of emotion into three sections: (1) physic emotion or feeling, (2) emotion of consciousness or attention, and (3) intellectual emotion. But the psychic level in its purity never appears in consciousness. Acts of attention engender consciousness by transforming brute feeling into what Collingwood calls "ideas." Collingwood characterizes the general form of consciousness as that of judgment. Consciousness is representational by virtue of being reflexive; that is, by virtue of a certain kind of self-consciousness. Thus, following by Collingwood, the organ that transforms feelings into ideas, makes them conscious, is the imagination: the imagination is that which transforms the flux of sensation into a coherent perceptual 
state, a perception in the proper sense of the word; the intellect is that which, in turn, subsumes those analogue representations under concepts. In this section, I will discuss key points for emotion from sociology, cultural psychology, cultural anthropology and feminism. All of these approaches help us to achieve cultural analysis. As Raymond Williams (1981: 12-13) states that culture is an aspect of the whole social order and cultures confer meaning. Cultures shape thoughts, feelings and activities by giving them intelligibility, but this does not mean that cultures shape individual attitudes and behaviors in a deterministic or exhaustive way. On the contrary, culture is endemic to everyday life consisting in practical, socially organized activities, cultural concepts, psychological phenomena, and human intentionality. Thus, emotion is cultural in my eyes because it is a meaningful expression through individual and collective action and interaction. We are supposed to talk about, think about, and imagine it seriously. Emotion is cultural because it connects with a distinct set of social practices. Emotion is cultural because it is associated with certain meanings. Emotion is cultural because it frequently appears in and is represented in everyday life.

\section{(1) Sociological Perspective}

Sociologist Arlie Hochschild (1979: 551 n2) defines emotion (feeling as interchangeable term) as bodily cooperation with an image, a thought, and a memory-a cooperation of which the individual is aware. Contrast to the assumption that emotions are natural responses arising from purely physical or psychological processes, sociologists attempt to make visible the ways in which positive or negative feeling or thinking is buried in words, social roles, social processes or social groups. They assume that emotional responses are preshaped and given form within a socio-cultural complex. That is, emotions are socially constructed, "interpreted, propagated, and deployed' (Jackson, 1993: 209). For instance, anger, hate, jealousy, love, compassion, indifference and disgust are all equally encouraged, elicited, forbidden or required in social life. In addition, Hochschild (1979) further points out two accounts of emotion: the organismic and the interactive accounts. The organismic viewpoint concerns the relation of emotion to biologically given instinct or impulse. In the interactive account, social influences permeate emotion more insistently, more effectively, and at mote theoretically posited junctures. To follow the interactive viewpoint, she also focuses on the term emotion management used synonymously with emotion work and deep acting in advance. Emotion work becomes an object of awareness most often when the individual's feeling do not fit the situation. Hochschild means emotion work as the act of trying to change in degree or quality an emotion or feeling. That is, to work on an emotion or feeling is the same as to manage an emotion or to do deep acting.

In classical sociology, Durkheim is more explicit about the role of emotions. Especially in his later works, he strongly implicates emotions and collective sentiments in the creation of social solidarity through moral community. Durkheim implies that "... what holds a society together — the "glue" of solidarity—and [Marx implies that] what mobilizes conflict - the energy of mobilized groups-are emotions" (qtd from Collins, 1990). In advance, Chris Shilling (2002: 18-19) suggests that we should connect emotion with Durkheim's social fact. ${ }^{2}$ Social fact may not appear to accord emotions much significance, but refers to a continuum of phenomena ranging from major institutional structures to types of feeling promoted by collective gatherings. In short, Durkheim represents the emotion in social or moral order. For him, the symbolic order is built around representations of what is sacred to group life; things set apart and forbidden from the profane, mundane world of everyday life.

In addition, Collins (1990) considers contemporary sociology such as symbolic interactionism has certain elective affinity with Durkheim. For instance, Goffman broaden Durkhiem in a way that shows how social order is produced on the micro-levels, and Garfinkel's breaching experiments $^{3}$ reveal sacred object very much like Durkheim's world. Collins (1990) also points out some limitations in studying emotions in this camp. For instance, Goffman focuses on the structure of micro-interaction, on its constraints, on the interplay between its subjective and objective components. Goffman is concerned with how ritual solidarity is generated in the little transient groups of everyday life, at the level of the encounter. Besides, Garfinkel demonstrates the most dramatically in his breaching experiments, in which he forces people into situations that cause them to recognize indexicality (i.e., they rely on tacit acceptance of what things mean contextually) and reflexivity (there are infinite regresses of justifying one's interpretations). The reaction of Garfinkel's subjects is always intensely emotional outburst.

\section{(2) Cultural Psychology and Anthropology}

Besides sociological perspective, cultural psychologist Carl Ratner (2000) gets ideas from Vygotsky to demonstrate that emotions are formed, reflected and functioned by cultural process. He considers that Vygotsky's conception is more specific and comprehensive than the standard general definition of culture as the totality of socially constructed behaviors, beliefs and objects. Cultural phenomenon is humanly constructed artifacts rather than natural products, and those cultural phenomena are social facts in Durkheim's sense of being emergent products of social interactions rather than individual creations. Thus, Ratner points out that

\footnotetext{
${ }^{2} \mathrm{~A}$ social fact is an abstraction external to the individual which constrains that individual's actions. That is, it is every way of acting, fixed or not, capable of exercising on the individual an influence, or an external constraint.

${ }^{3}$ Garfinkel's experiments, violating the sacred object, call forth the same effects as would violating a ritual taboo for a tribal member, desecrating the Bible for a Christian, or defaming the flag for a patriot.
} 
emotions are socially constructed artifacts which are functionally independent of biological determinants. He also emphasizes that emotional characteristics reflect (recapitulate) the social organization of activities and the cultural content of concepts. In short, cultural psychology can be seen as a movement attempting systematically to analyze values and underlying presupposition taken for granted in the intentional world.

For Jerome Burner, cultural psychology neither dismisses what people say about their mental states, nor treats their statements only as if they were predictive indices of overt behaviors. What is takes as central, rather, is that the relationship between action and saying (or experiencing) is, in the ordinary conduct of life, interpretable. It takes the position that there is a publicly interpretable congruence between saying, doing, and the circumstances in which the saying and doing occur. That is to say, there are agree-upon canonical relationships between the meaning of what we say and what we do in given circumstances, and such relationships govern how we conduct our lives with one another (Bruner, 1990: 19). In other words, cultural psychology will not be preoccupied with behavior but with action, its intentionally based counterpart, and more specifically, with situated action-action situated in a cultural setting, and in the mutually interacting intentional states of the participants. Thus, cultural psychology emphasizes emotion as "...emotions are characterized by attitudes such as beliefs, judgments, and desires, the contents of which are not natural, but are determined by the systems of cultural belief, value, and moral value of particular communities" (Armon-Jones, 1986: 33)

In the similar way, Lyon (1998: 42) states that anthropological understanding of emotion has generally been achieved through more detailed and refined cultural analysis ${ }^{4}$. Lyon also points out that the cultural anthropological study of emotion seeks at base to understand the ways that innerness is shaped by culturally laden sociality. This view closely follows the work of Clifford Geertz in its insistence that meaning is a public fact, that personal life takes shape in cultural terms that individuals are necessarily and continually involved in the interpretive apprehension of received symbolic models. That is, emotions are central to the understanding of the communicative and associative functions of the body. Emotions activate bodies in ways that are attitudinal and physical and that have implications for the way individuals together create a common design, purpose, or order (Lyon, 1998: 53).

In this vein, emotion must occur in a social-relational context, and it is also the pivot upon which cultural ritual turns. As Geertz (1973: 449) argues in Balinese cockfight, ritual display serves as a kind of sentimental education in

\footnotetext{
${ }^{4}$ Please also refer to Michelle Rosaldo's (1984) “Toward an anthropology of self and feeling" and Catherine Lutz's (1988) discussion of the cultural construction of emotion in "Unnatural Emotions: Everyday Sentiments on a Microensian Atoll and Their challenge to Western Theory."
}

its use of emotion for cognitive end. Ritual is performative as well as representational, and ritual refers to the norm which is the prescribed code that societal members must follow. In my opinion, the action or ritual of the norm also accounts for "common script" the term used by Evring Goffman (1959). He points out that culture frames social interactions and is reshaped by these interactions. Culture further establishes the roles that individuals might adopt as they engage in any social interaction. Thus, culture is not only a stage upon which the actors weave their narratives, but culture is also the script inscribed norms into actors' bodies.

\section{(3) Feminist Approach}

Finally, feminism is also an important approach to debate emotional issues. Feminist treatments of the question of emotion (e.g., Jagger, 1989) have tended to portray emotions not as chaos but as a discourse on problems. Certain feminists have contested both the irrationality and the passivity of feelings by arguing that emotions may involve the identification of problems in women's lives and are therefore political. Talk about anger, for instance, can be interpreted as an attempt to identify the existence of inappropriate restraint or injustice. By extension, talk about the control of emotions would be, in this feminist discourse, talk about the suppression of public acknowledgement of problems. Thus, Megan Boler (1998) defines "feminist politics of emotion" as the explicit analysis, and resulting in individual or collective actions, that challenge the historical and cultural emotional rules which serve to maintain patriarchal hierarchy, particularly with respect to the arbitrary gendered division of public and private spheres.

In general, a feminist politics of emotion examines specific strategies for women to exorcise the internalized effects of women's subordinate status within patriarchal ideologies by means of developing alternative emotional responses, expressions, articulations, identities, and visions. As Fisher (1981: 20, 23) points out that "feeling helps us [women] define what the world is like and how we want to change it....The exploration of feelings and experiences can help us define the basic arena for feminist theory and the basic direction for feminist action." The best example comes from Sue Campbell's (1994) work, which builds on recent feminist philosophical analyses of bitterness to complexify "experience" and "emotions" by situating them within collaborative social contexts that cannot be reduced to either individualized expressions of emotion, nor to simply rational/irrational experiences. Campbell reclaims bitterness as a "legitimate and rational" response to injustice or oppression. Further, to be told "you're bitter" is a dismissal and a silencing. Even if you then articulate your reasons for being bitter the other is no longer listening. If instead we recognize that bitterness is collaboratively and publicly formed, it does not make sense to require the bitter individual to justify her reasons. Rather, what is called for is a full social accountability on everyone's part for the 
interpretive context. Campbell elaborates a framework that does not rely simply on a rational/irrational evaluation of emotions, but rather understands emotional expressions as concretely situated particular historical or socio-cultural relationships. Thus, in feminist debates, an emotional experience is not simply reflective of one's individualized experience but rather reflects the interactive dynamics of power between persons.

In the educational field, Weiler also suggests that the assumptions of a collective experience of oppression do not address the realities of the classroom. Attempting to name and struggle against oppression can be demanding if not impossible in the classroom because of the range of emotions that are engaged and even those best intentioned may well retreat to more traditional practices rather than confront the various issues involved. The key question to confront is that of commonality of experience of oppression and the need to define it in the "context of historically defined struggles" (Weiler, 1991: 451). In relation to this particular issue, Weiler challenges Freire's pedagogy and his premise that all people are subjects and knowers of the world She contends that he does not acknowledge the possibility of a contradictory experience of oppression and concludes that she is arguing for "a more situated theory of oppression and subjectivity, and for the need to consider the contradictions of such universal claims of truth or process" (1991: 456).

\section{Emotion and Culture: Emotion as Social Act and Rhetorical Expression}

In my opinion, to combine with these cultural approaches for emotion research, we should portray culture as "collective representations"-vocabularies, symbols, or codes - that structure people's abilities to think and act. In addition, we also should focus on groups use collective representations in everyday interaction. Actors make meaning with collective representations, and they do so in a way that usually complements the meaningful, shared ground for interaction. Thus, in this following discussion, I divide emotion into two parts: emotion as a social act and emotion as rhetorical expression.

\section{(1) Emotion as a Social Act}

Gordon (1990: 146-154) mentions emotions include bodily sensations, expressive gestures and actions, a social situation or relationship, and emotional culture. In short, we can say that emotion as a social act. Generally speaking, a social act is located in social and cultural factors, and it goes onward to incorporate others, as well as move toward a presumed end. That is, a social act involves other people: it is the participation with at least one other in the construction of stable meanings, relationships and worlds. Furthermore, these acts take place in situations. A situation is an encompassing arrangement of space, objects, and persons designed to elicit determinate responses from agents and serves as the locus in which words are exchanged by participants in a social act, and leading to further refinements and redefinitions. In the real ordering of life, it will be difficult to separate an act from its situation because all acts are in fact situated. Thus, social acts represent the inner mechanism of selection and exclusion in each situation and interaction: they involve the selection of means, proper strategies, and investment of effort and interest, and are addressed to a presumptive audience. In this lens, social actors are seem effectively cultural dopes, to use Harold Garfinkel's (1967) term, who internalize passively extant social roles and behavioral norms, thus acting to reproduce social structures and institutions. For instance, schoolteachers typically avoid talking about emotions in public, to handle emotional situations as well as emotional feelings, and to deal with people, situations and emotions seriously. Thus, we can say that this avoidance for talking emotions in their everyday lives as a dominant or sacred belief, which are authorized and inscribed in subjectivities, institutional arrangement, and various cultural narratives. In sum, emotions are controlled and managed in everyday lives and transcend the divides between mind and body, nature and culture, structure and action. Thus, emotional responses raise validity claims which can be challenged or confirmed and that, like any cognitive belief, an emotional response is something that we believe we can talk people out of when they are wrong (i.e., when their emotional response is irrational).

However, we should also focus on the idea of parody as one act of emotional expression. For Bakhtin (1981), parody is a corrective of reality. Embodying dual intentions, it contains both the meanings of the author/agent and the refracted meanings of the parodied text or situation. Parody can bolster cultural barriers as well as break them down. In some situations, parody functions to release tension, thereby preserving the status quo. In other words, it offers opportunities for opposition tempered by humor, and also provides a space for critique and change. As Bakhtin has pointed out, "the words in an emotional vocabulary or speech genre are neutral in terms of the feeling aspect of emotion. Even a word such as joy, which carries the meaning of happiness, can be used to the contrary depending on the expressive intonation it is given, as in the phrase any joy is now only bitterness to me" (Bakhtin, 1986: 87). Expressive intonation does not have to follow the meaning of the word itself: in fact, it can be juxtaposed against that meaning as in irony, sarcasm or wit.

\section{(2) Emotion as Rhetorical Expression}

Second, according to cultural psychology, all emotions are also intentional (that is, they refer to something), and emotions can exist only in the reciprocal exchanges of a social encounter. We should be so curious what the emotion vocabularies are, and under what conditions they are used. Generally speaking, emotional culture includes vocabularies 
(words for emotions) ${ }^{5}$, norms (regulation expression and feeling), and beliefs about emotions (i.e., the idea that repressed emotion is disturbing). Vocabularies of emotion are the varieties of public discourses which statements about their feeling toward certain events. In particular, cultural vocabulary of words used to identify emotions of self and others. A vocabulary is composed of labels for emotions that (1) common experiences for many members, (2) centered on significant concerns in social interactions, and (3) sufficiently distinguished as units (Gordon, 1990). Language is functional as a communicative medium only within a community of competent language user. This requires knowledge of a language system which exists for individual prior to and independent of specific interaction situation. The language system works for a community of users because of its structural properties, that is, as a set of implicit linguistic rules through which messages may be negotiated but the rules, themselves, are not subject to negotiation. Thus, language itself contributes to the cultural construction of emotions, and language is a means by which we participate in creating a shared sense of what emotions are.

Similarly, Harre (1986) considers that meanings are defined by reference to shared language, cultural beliefs and values and the ways in which an individual is positioned in social encounters. However, sometimes irrelevant symbols or marks can be only what one use the word for anger, or something roughly approximating it in their culture, to pick out, this is because they share the language and common emotion culture (like Martian language such as orz in current Taiwan MSN culture). Thus, this emotional textualization is a particularly strategy because it allows people to express an authentic feelings without necessarily take an oppositional stand against authoritative institutional setting. ${ }^{6}$ (However, I think we also must be careful to suspend any assumptions we may have about the viability of cross-cultural translations of vocabularies and interpretations of practices, upon which any theory of universal emotions must depend, to wait upon proper and careful empirical research.) Thus, emotional textualization as "linguistic outlet" implies that a certain kind of emotional expression takes place in certain situations via rhetoric expressions.

The emotional vocabulary and the discursive consciousness constitute complete the emotional experiences. We can see how emotion is a complex in which the feeling or expressive intonation with which

\footnotetext{
${ }^{5}$ Sometimes, feeling and emotion words do not always correspond. This idea represents Vygotsky's argument on the relation between thought and words (Vygotsky, 1987: 250), that feeling is expressed but completed in the word as emotion. This means that feeling is restructured as it is articulated consciously through words as an emotion. The feeling goes through a transformation as it finds utterance in words - it becomes like an gbject that can be reflected upon.

The analytic object of textualization includes the printed word, graphic images, spoken utterance, and even the messages given off in social settings by such behaviors as bodily movements and positions (which we correctly refer to as body language), gestures, facial expressions, and so on. In addition, we should consider certain social conditions might be associated with either restricted or elaborated emotional codes in Basil Bernstein's context.
}

words or phrases are said is used as a counterpoint to discursive meaning, creating the full spectrum of emotion. For instance, laughter offers subversive liberation from what these theorists call the "univocal" appearance of naturalness of our social world (e.g., Baudrillard, 1981, Bakhtin, 1981). Such theory assumes that what is shared is oppressive. Laughter is a particular kind of expression, imbued at once with a myriad of possibilities: appreciation, surprise, recognition, irony, sarcasm, understanding, sympathy, disgust, enjoyment, puzzlement, concern, disdain-an embodied political position, a kind of representation. In critical pedagogy camp, Peter McLaren also considers laughter as "a political refusal...reinvoking the fool and itinerant clown as pedagogical agents of resistance" (McLaren, 1993: 287). Subversive humor only expresses the discontents of the present. Like Scott (1990) argues that we should not see any basic contradiction between mild and strong, hidden and open forms of subordinate protest. His framework abolishes a contradiction of long standing between apparent apathy and protest, "false" and "true" consciousness. Subversive humor expresses the discontent with anger, frustration, fear and anxiety. These emotions are responses to the "social experience of indignities, control, submission, humiliation, forced deference and punishment" associated with any form of domination (Scott, 1990: 111-113).However, for social movement activists, the evolutionary force from laughter is quite different from traditional strategies in social movement such as underground press and sit-in protest to combat institutional hegemony. The political joke or humor may reveal certain fact in the school or educational field and represent the implication of irony and satire, but it depends on the proper timing and sense of humor without faithful commitment for educational change. That is, sometimes laughter has the implication of nihilism in this sense. In my opinion, laughter is the inner mechanism of buffer, but laughter is impossible to subvert dominant hegemony.

\section{Emotion in Teachers' Everyday Lives}

\section{(1) Emotion and Practice}

As I discussed above, emotions can be managed in accordance with certain conventions, that there is some intentionality involved in the expression of emotion. Hochschild (1983) has argued that emotional life is largely socially-regulated by ideologies of feeling, operating through a series of "feeling rules" which prescribe how individuals ought to feel in various situations: an individual who does not happen to feel spontaneously in accord with a particular rule will engage in a form of "emotion work" to try to act the appropriate emotion or to influence in the way others feel. In my opinion, Hochschild's discussion of "feeling rules" offers insights as to how such discourses - which embody ideologies of feeling — influence emotional states and behaviors. Thus, Hochschild's 
discussion of emotion may also help us to throw light on the processes whereby teachers try to adapt to disappointment of their expectations of relationships with educational system. Teachers have internalized the feeling rules, and they engaged in different levels of acting effort: surface acting does not obscure what is really felt, but under more powerful pressure deep acted feeling obscures the authentic, even for the actors themselves. This is the so-called feeling rule sharing some formal properties with other sorts of rules. It delineates a zone within which one has permission to be free of worry, guilt, or shame with regard to situated feeling. That is, feeling rules refer to guidelines for the assessment of fits and misfits between feeling and situation. Feeling is subject to individual and social management, that "in managing feeling we contribute to the creation of it" (Hochschild, 1983: 18), that our senses of what emotions are culturally specific (Lutz, 1986; Rosaldo, 1984), and that "there are complex linguistic and other social preconditions for the...existence of human emotions" (Jagger, 1989: 15). In addition, Thoits refers to feelings that do not fit norms for emotions as deviant emotions. As she expresses, "emotional deviance refers to experiences or displays of affects that differ in quality or degree from what is expected in a given situation" (Thoits, 1990: 181). Thus, the deviant emotions produced in such conflicting positioning must be consciously managed or unconsciously repressed in order to fit the prevailing definition of the situation.

Emotion seems the structuring structure in Bourdieu sense that makes it possible for the world to be intelligible to us while, at the same time, configuring our bodies as disposed to certain feelings and actions. These feelings themselves may become habitual so that it is possible for certain people to produce patterns of responses to situations that tend to characterize them. In my opinion, the usual deviant emotions in schoolteacher's everyday lives include perplexity, mope/boredom, and anger/resentment. Generally speaking, perplexity is trouble or confusion resulting from complexity. Then, boredom is a type or form of anxiety about the lack of meaningfulness of an activity, a condition and (possibly) a life," and boredom is "restless", "irritable" and presses one to construct meaning. Similarly, mope means to give oneself up to brooding, or to become listless or dejected situation. Finally, resentment is often used with a feeling of indignant displeasure or persistent ill will at something regarded as a wrong, insult, or injury. In short, resentment is a feeling of deep and bitter anger and ill-will. All of these three emotional statuses in schoolteachers' everyday lives represent the characteristic of the deskilling teachers ${ }^{7}$ : it means the constructing process of alienation and

${ }^{7}$ Deskilling is one type of alienation. Seeman (1959) defines five variants of alienation: powerlessness, meaninglessness, normlessness, isolation, and self-estrangement. In a later article, Seeman (1972) revised these categories and defined six variants of alienation: powerlessness, meaninglessness, normlessness, cultural estrangement, self-estrangement, and social isolation. In educational studies, Apple (1995) is a significant scholar to identify how the centralization of curriculum design might lead to deskilling teachers. Apple shows that deskilling carries with it certain isolation from their teaching. If I can propose the proper example about deskilling teachers, LeCompte and Dworkin using the terms burnout and quitting behavior (deviant emotions) to refer to teachers' everyday lives would be a good one. Burned-out teachers suffer from entrapment; that is, teachers without goals, on the contrary, students without purpose; they are alienated, but cannot quit. They define burnout as follows: "Burnout is an extreme form of role-specific alienation characterized by a sense that one's work is meaningless and that one is powerless to effect changes that could make the work more meaningful. Further, this sense of meaninglessness and powerlessness is heightened by a belief that the norms associated with the role and the setting are absent, conflicting, or inoperative, and that one is alone and isolated among one's colleagues and clients" (LeCompte \& Dworkin, 1991: 94).

However, it is important for us to notice "elements of good sense as well as bad sense" (Gramsci, 1971) in emotional issue. Of course, teachers are not passive internalizers of pregiven social or cultural messages. This involves a continual process of compromise, conflict, and active struggle to maintain hegemony. Like Willis (1977: 175) says in Learning to Labor, "Social agents are not passive bearers of ideology, but active appropriators who reproduce existing structures only through struggle, contestation and a partial penetration of these structures." In Willis's context, penetration refers to those instances where students has developed responses to school and work that see the unequal reality they will face. Their rejection of so much of the content and form of day to day educational life bears on the almost unconscious realization that, as a class, schooling will not enable them to go much further than they already are. The culture the lads create inside and outside their schools actually constitutes a rather realistic assessment of the rewards of the obedience and conformism that the school seeks to extract from working-class youths. (However, I need to remind readers that informal cultural resistances sometimes may act in contradictory ways that ultimately tend to be reproductive. ${ }^{8}$ )Like Bourdieu uses "practical knowledge" and "sense of practice" to describe the practical dimension of action. Actors are not rule followers or norm obeyers but strategic improvisers who respond dispositionally to the opportunities and constraints offered by various situations.

For Bourideu, practice refers to action that is oriented to practical outcomes, is strategic, and is largely organized by

characteristics, such as "rule orientation", "greater dependability" and "the internalization of the enterprise's goals and values" (Apple, 1995: $140-141)$.

${ }^{8}$ We should consider the possibility that resistance is not only choice against domination but conformism, ritualism, or euphemism, even sitting on the fence. For instance, Woods (1979: 71-72) notes in his work The Divided School, there are many modes of pupil adaptation to be found in schools - conformity, ritualism, retreatism, colonization, intransigence, and rebellion being the major ones. To focus on resistance as the only form opposite to cultural reproduction is to ignore much of what happens in reality. Emotional reaction which is quite different from resistance could be significant dimensions for future research. 
unconscious schemes, so that it operates an intuitive skill or tact. Practice cannot follow "logical logic" first because of its relation to time. Bourdieu stresses that for practice, unlike logic, "its temporal structure, that is, its rhythm, its tempo, and above all its directionality, is constitutive of its meaning" (1977: 81). Practice requires instantaneous judgments anticipating future actions, as when "a player who is involved and caught up in the game adjusts not to what he sees but to what he fore-sees...in response to an overall, instantaneous assessment of the whole set of his opponents and the whole set of his team-mates, seen not as they are but in their impending positions." He does so under conditions of "urgency" that "exclude distance, perspective, detachment, and reflection" (1977: 81-82). ${ }^{9}$ In sum, emotional expressions are strategic, playing roles on forms of action, and actions occur in situations. Thus, emotions are experienced positionaly in terms of merging and establishing boundaries in one's relationship with others.

\section{(2) Structure of Feeling}

Collins (1990) identifies two types of emotions: (1) transient emotions such as joy, embarrassment, fear, and anger, which are dramatic and disruptive of the flow of everyday life; and (2) emotional energy, which is a long-term emotional tone that is durable from situation to situation. Emotional energy increased can be built from solidarity experiences based in interaction. There could be face-to-face interaction or another interaction through technology, shared emotion, a shared focus of attention, and a mutual awareness of this focus. In the educational context, this shifts teachers' awareness from themselves to the structural issues. Thus, this will form the possibility of "structure of feeling in teacher's community" borrowing from Raymond William's concept structure of feeling. ${ }^{10}$ In my opinion, structure of feeling is a significant mechanism for mobilization of emotion, which brings the possibility for social transformation. Williams (1977: 132-133) describes this as a "social experiences in solution." He talks of structures of feeling to indicate the sense people have of changing social meanings and values as they are actively

\footnotetext{
${ }^{9}$ Bourdieu gets certain insight from Goffman, who argues that social life could be understood as a form of "strategic interaction." His dramaturgical analysis suggests that, in practice, social life is a game, that human activity is strategic (contingent on the responses of others) and is unscripted (Goffman, 1969). However, Goffman's arguments seem to ignore the unconscious side in action.

${ }^{10}$ In the similar argument, Giambattista Vico's "sensus communis" is originally a notion of the shared "communal sense" that facilitates communicative understanding. The proper translation in English is "communal sense" or "joint understanding." Sensus communis is based upon experience which results in acquiring the common good through living in the community (Schaeffer, 1990). In addition, we should also clarify two interesting terms related to this issue: verstandigung and einverstandnis. Einverstandnis (in Habermas's writings) translates as "a well-grounded agreement"- that is, one that has been reached in a process of genuine argumentation (discourse). On the contrary, verstandigung suggests less the state of having reached agreement than the process of reaching agreement. In short, Habermas refers to Verstandigung as a process - as the bringing about a consensus (einverstandnis) (Cooke, 1994: $185)$.
}

lived and felt in the present moment. Williams is indicating the sense of changing meanings and values by which people act in the present moment, in a social context that is not ossified but is a continuous and living present. Thus, meanings and values are not stable and fixed but are in a constant process of change and modification. While people may not have clear ideas about the way these meanings and values are changing they nevertheless feel this in their social relations. In other words, Williams contrasts feeling to discursive elements such as worldview and ideology which are linguistic and textual.

Furthermore, in its ideal situation, the structure of feeling in teacher's community enables solidarity among schoolteachers, through emotional responses to educational events or policy and so on, which is shaped by certain activities occurring within the context of socially organized space. Thus, different teachers' divergent emotional expressions and opinions function as the collective identity process via story-telling or life narrative. This process, as a social transaction, engages the various schoolteachers in a communicative relationship: that is, the storyteller and reader/listener create a "we" involving some degree of affective bond and a sense of solidarity: told and retold, "my story" becomes "our story" (Davis, 2002). Thus, I agree completely that narratives will facilitate collective identity, as Rosaldo (1984: 143) says, "Feeling is not substances to be discovered in our blood, but social practices organized by stories that we both enact and tell. They are structured by our forms of understanding." In short, within culture public and private narratives or emotional expressions often overlap and intermesh, private narratives become public which offer opportunities for narrative disclosure or emotional expression around educational concern. ${ }^{11}$

In my opinion, the emotional energy from intense solidarity with similarly positioned people can create collective identity. Collective identity provides a meta-perspective on one's self. When collective identity is formed around previously repressed deviant emotion, the meta perspective provided by collective identity can allow room for the legitimization of these emotions. When one can see one's self from a meta perspective, one can come to see one's own experience as part of a larger pattern rather than an individual experience of fear, inadequacy, lack of fulfillment, depression, or unhappiness. What's more, Collins (1990: 31) emphasizes that high emotional energy is experienced as "solidarity feelings, moral sentiment, the enthusiasm of pitching oneself into a situation, or being carried along by it." Emotional energy is long-term level of enthusiasm, personal strength, a sense of social

\footnotetext{
11 For instance, Summers-Effler (2002) points out that when collective identity is formed around previously repressed deviant emotions, the meta perspective provided by collective identity can allow room for the legitimization of these emotions. That is, one's own experience is part of a larger pattern rather than an individual experience of fear, depression, or unhappiness. Through solidarity, deviant emotions come to represent less a threat to one's social bonds, and collective identity can end the energy drain associated with a meeting between social conflict and the self.
} 
connectedness, and/or willingness to initiate interaction. On the contrary, perplexity, mope/boredom and anger undermine potential participation in subversive activity. They are the result of feeling overwhelmed with negative expectations. As Collins (1990: 43) states, "truly powerful persons do not become angry in a sense, because they do not need to; they get their way without it." Thus, Collins suggests that an emotional motivation for action offer a base for explaining the resilience of power structure as well as the potential for social change. The commitment to process and action requires a radical rethinking of values and what counts as knowledge. Central to the reconceptualization of values and knowledge is an emphasis on the importance of everyday life's experience and emotions in particular as a barometer of both oppressive and liberatory experiences. Thus, how to shift emotional energy from anger/resentment to joy and commitments becomes the task of critical pedagogy.

Perplexity followed with high emotional energy manifests itself as anger/resentment, which is the temporary energy to overcome an obstacle. Collins (1990: 44-45) points out righteous anger which is the emotional outburst shared by a group against persons who violate its sacred symbols. Such anger only happens when there is a previously constituted group; one cab predicts that righteous anger is proportional to the amount of emotional charge of membership feelings around particular symbols. On the contrary, Collins also states that low emotional energy results in feelings of "depression, alienation, and embarrassment" (1990: 31). I would also add that low emotional energy is a feeling of mode/boredom. Critical pedagogy emphasizes language of hope is required to inspire subversive action. I think large amount of emotional energy can create the hope necessary for subversive activity despite realistic appraisals of potentially deadly risk. High level of emotional energy is a crucial step in connecting anger to social change. Thus, Collins (1990: 31) states that high emotional energy is experienced as "solidarity feelings, moral sentiment, the enthusiasm of pitching oneself into a situation, or being carried along by it." That is, high emotional energy is a feeling of positive expectations for language of hope.

Critical pedagogy creates a condition for transformation

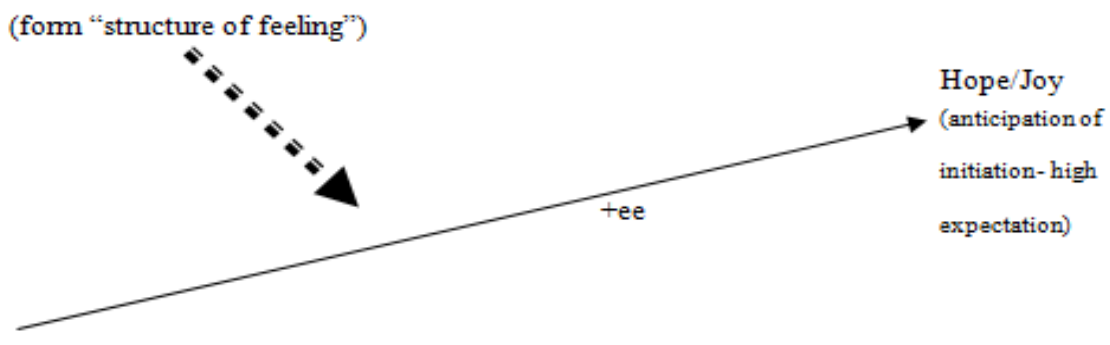

Anger/Resentment (temporary energy to overcome an

obstacle)

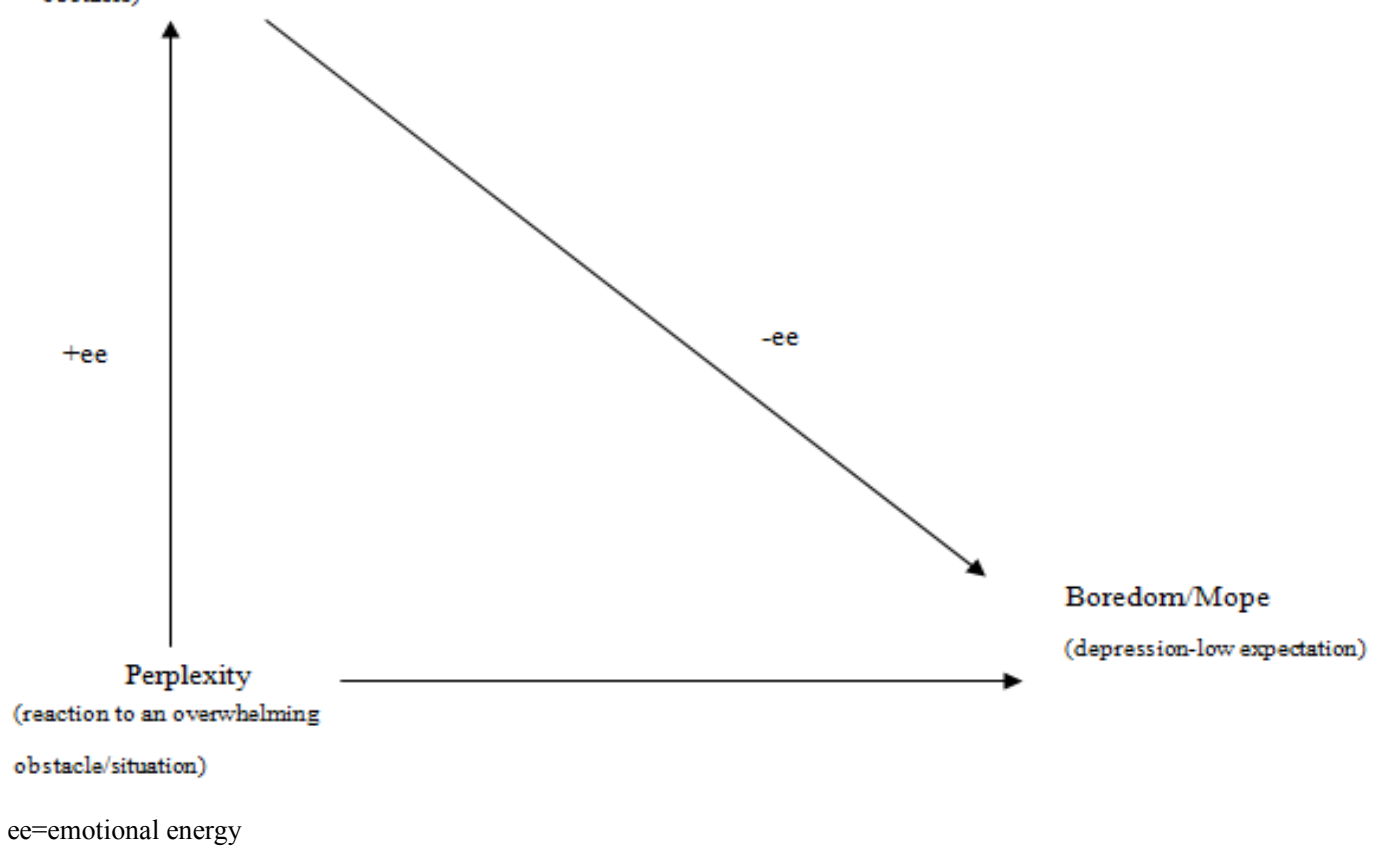

Figure 1. The Emotional Requirement for Subversive Action 
Although Paulo Freire (2004) in Pedagogy of Indignation sees anger as the appropriate response to obscene violations of human rights and social injustices; anger is a tool that will enable all those who yearn for social justice to recapture their human dignity and avoid falling into cynicism. I do not totally agree Freire's argument here; indeed, I still think about revolutionary actions that are based on "joyful" commitment not universal envy or existential resentment, as Nietzsche (1968: 68) states: "being able to dance with the feet, with concepts, with words: do I still have to say that one has to be able to dance with the pen?"12 In my eyes, social change must occur in euphoric moods which affirms collective identities and beliefs, as well as their strategies. As Durkheim sensed, "collective ritual and gatherings suggest that you are participating in something bigger than you: you are part of history, or you are morally sanctioned, or you truly belong to a group. The emotion of rituals reinforce cognitive and moral visions as well" (Jasper, 1997: 197).

\section{Conclusion: Dialogue with Paulo Freire}

In critical pedagogy, Freire argues for an ethic of humanization, based on radical democratic political principles ${ }^{13}$ and grounded in a rereading of humanist traditions (Aronowitz, 1993). That is, the dynamic relations between knower and known is not merely an unreflective being-in-the-world, but an active consciousness involving the deliberate use of the imagination, the emotions, and the ability to conjecture and compare (Freire, 1998). ${ }^{14}$ For instance, Freire's notion of conscientization ${ }^{15}$ or consciousness raising, is a political act in which oppressed people are raised from their oppressed stupor to recognize that oppression and to move from being passive pawns in the system to active transformers of the oppressive system. That is, the manner in which oppressed people emerge from their submersion in the oppressor/oppressed relationship through conscientization is structurally similar to how students get to know reality generally, namely, being conscious of their conscious relation to objective reality. Thus, consciousness (rational) is a condition for knowledge, and Freire believes

\footnotetext{
12 Maybe we need meta-thinking about this in the future: can anger or resentment become motivation for social movement?

${ }^{13}$ In Laclau's opinion, radical democracy opens new positions of speech and thus both empowers previously excluded groups and enables new aspects of social life to become part of the political process (Laclau, 1990). That is, radical democracy is a strong way to empower people, and participation is the central creative mechanism mediating between institutions and motives. Public discussion is seen as a mechanism ensuring that any political action has to pass the test of public consent.

${ }_{14}$ As Freire says, "curiosity as restless questioning, as movement towards revelation of something hidden, as a question verbalized or not, as search for clarity, as a moment of attention, suggestion, and vigilance, constitutes an integral part of the phenomenon of being alive" (Freire, 1998: 38).

${ }^{15}$ Freire's notion of "conscientizacão," which is a process that invites one to engage the world and others critically through reading the word and the world. In this process, knowledge emerges in dialectical relationship wherein meaning is made as a product of dialogue between or among individuals. Meaning is constructed through reciprocal dialogue and not within a single person or subject.
}

that knowledge always is actively manufactured, in dialogue: knowledge is constructed by a conscious relation to the world. However, in my argument, sometimes the camp of critical pedagogy overemphasizes consciousness or rational, and this will lead researchers to focus on the dimension of domination and struggle instead of emotion while they interpreting the relevant issues in educational fields. Like Boler (1999) mocks the phenomenon of Freire's work base on CR being heroized. Weiler (1996) suggests that much of this literature constitutes a "canonization of Freire," and thus a betrayal of the ideals Freire himself is calling for.

In my conclusion, both emotional solidarity and rational deliberation are equally significant. On the one hand, I agree that liberation is defined not as an ideal state of mind or as an endpoint but as a process of active, dialogical, critical striving to be more. On the other hand, I consider that emotional express and unconsciousness are also the part of this struggling process. For instance, Eliasoph (1998: 93) explores solidarity that operates without words: a culture's rhythms, sounds, and emotions can create a kind of physical togetherness, meanings that cannot be reduced to words or beliefs or ideas but that have to be experienced in practice. That is, social change sometimes happens on emotional forms of communication over rational ones.

\section{REFERENCES}

[1] Apple, Michael W. (1995). Education and Power, $2^{\text {nd }}$ edition. New York: Routledge.

[2] Armon-Jones, Claire. (1986). "The Thesis of Constructionism." In Rom H'arre (ed.), The Social

[3] Construction of Emotions (pp. 32-56). New York: Blackwell.

[4] Aronowitz, Stanley. (1993). "Paulo Freire's radical democratic humanism." In Peter McLaren and

[5] Peter Leonard (eds.), Paulo Freire: A Critical Encounter (pp. 8-24). New York: Routledge.

[6] Bakhtin, Mikhail M. (1981). The Dialogic Imagination. Austin: University of Texas Press.

[7] Bakhtin, Mikhail M. (1986). Speech Genres and Other Late Essays. Austin: University of Texas Press.

[8] Baudrillard, Jean. (1981). For a Critique of the Political Economy of the Sign. St. Louis: Telos Press.

[9] Boler, Megan M. (1998). "Towards a Politics of Emotion: Bridging the Chasm Between Theory and Practice," American Philosophy Association Newsletter, 98(1): 49-54.

[10] Boler, Megan M. (1999). "Posing Feminist Questions to Freire." In Peter Roberts (ed.), Paulo Freire and Education: Voices from New Zealand. Auckland: Dunmore Press.

[11] Bourdieu, Pierre. (1977). Outline of a Theory of Practice. Cambridge: Cambridge University Press. 
[12] Bruner, Jerome. (1990). Acts of Meaning: Lectures on Mind and Culture. Cambridge, MA: Harvard University Press.

[13] Campbell, Sue. (1994). "Being Dismissed: The Politics of Emotional Expression”, Hypatia 9(3): 46-65.

[14] Collins, Randall. (1990). "Stratification, Emotional Energy, and the Transient Emotions." In Theodore

[15] D. Kemper (ed.), Research Agendas in the Sociology of Emotions (pp. 27-57). Albany: State University of New York Press.

[16] Collingwood, Robin G. (1958). The Principles of Art. Oxford: Oxford University Press.

[17] Cooke, Maeve. (1994) Language and Reason: A Study of Hebermas's Pragmatics. Cambridge, MA: The MIT Press.

[18] Davis, Joseph E. (2002). "Narrative and Social Movements." In Joseph E. Davis (ed.), Stories of Change: Narrative and Social Movement (pp. 3-29). Albany, NY: State University of New York Press.

[19] Douglas, Mary. (1966). Purity and Danger: An Analysis of the Concepts of Pollution and Taboo. London: Routledge.

[20] Eliasoph, Nina. (1998). Avoiding Politics: How Americans Produce Apathy in Everyday Life. Cambridge: Cambridge University Press.

[21] Fisher, Berenice M. (1981). "What is Feminist Pedagogy?", Radical Teacher, 18: 20-24.

[22] Freire, Paulo. (1998). Pedagogy of Freedom: Ethics, Democracy, and Civic Courage. New York: Rowman \& Littlefield.

[23] Freire, Paulo. (2004). Pedagogy of Indignation. Boulder, CO: Paradigm.

[24] Garfinkel, Harold. (1967). Studies in Ethnomethodology. Cambridge: Polity Press.

[25] Geertz, Clifford. (1973). The Interpretation of Cultures. New York: Basic.

[26] Goffman, Evring. (1959). The Presentation of Self in Everyday Life. Garden City, NY: Doubleday.

[27] Goffman, Evring. (1969). Strategic Interaction. Philadelphia: University of Philadelphia Press.

[28] Gordon, Steven L. (1990). "Social Structural Effects on Emotions.” In Theodore D. Kemper (ed.), Research Agendas in the Sociology of Emotions (pp. 145-179). Albany: State University of New York Press.

[29] Gramsci, Antonio. (1971). Selections from the Prison Notebooks. New York: International.

[30] Hargreaves, Andy. (1998). "The Emotional Politics of Teaching and Teacher Development: With Implications for Leadership", International Journal of Leadership in Education, 1(4): 315-336.

[31] Harre, Rom. (1986). "The Social Constructionist Viewpoint." In Rom Harre (ed.), The Social Construction of Emotions (pp. 1-14). New York: Blackwell.

[32] Higgins, E. Tory. (1987). "Self-Discrepancy: A Theory Relating Self and Affect", Psychological Review, 94:
319-340.

[33] Hochschild, Arlie R. (1979). "Emotion Work, Feeling Rules, and Social Structure", American Journal of Sociology, 85(3): 551-575.

[34] Hochschild, Arlie. R. (1983). The Managed Heart: Commercialization of Human Feelings. Berkeley: University of California Press.

[35] Jackson, Stevi. (1993). "Even Sociologists Fall in Love: An Exploration of the Sociology of Emotions." Sociology 27(2): 201-217.

[36] Jagger, Alison M. (1989). "Love and Knowledge: Emotions in Feminist Epistemology.” In Alison M.

[37] Jagger and Susan R. Bordo (eds.), Gender/Body/Knowledge: Feminist Reconstructions of Being and Knowing (pp.145-171). New Brunswick: Rutgers University Press.

[38] Jasper, James M. (1997). The Art of Moral Protest: Culture, Biography, and Creativity in Social Movements. Chicago: University of Chicago Press.

[39] Krantz, Rebecca S. (2003). Practicing Creative Democracy: Participatory Neighborhood Planning, Community Organization, and Pragmatist Sociology in Madison, Wisconsin. Unpublished Dissertation, Department of Sociology, University of Wisconsin-Madison.

[40] Laclau, Ernesto. (1990). New Reflections on the Revolution of Our Time. London: verso. LeCompte, Margaret D., and Dworkin, Anthony G. (1991). Giving Up on School: Student Dropouts and Teacher Burnouts. Newbury Park, CA: Corwin.

[41] Lutz, Catherine A. (1986). "Emotion, Thought and Estrangement: Emotion as a Cultural Category", Cultural Anthropology, 1: 287-309.

[42] Lutz, Catherine A.(1998). Unnatural Emotions: Everyday Sentiments on a Micronesian Atoll and Their Challenge to Western Theory. Chicago: University of Chicago Press.

[43] Lyon, Margot L. (1998). "The Limitations of Cultural Constructionism in the Study of Emotion." In Gillian Bendelow and Simon J. Williams (eds.), Emotions in Social Life: Critical Themes and Contemporary Issues (pp. 39-59). New York: Routledge.

[44] McLaren, Peter. (1993). Schooling as a Ritual Performance: Towards a Political Economy of Educational Symbols and Gestures, $2^{\text {nd }}$ edition. New York: Routledge.

[45] Nietzsche, Friedrich. (1968). Twilight of the Idols and The Anti-Christ. Baltimore, MD: Penguin.

[46] Ratner, Carl. (2000). "A Cultural-Psychological Analysis of Emotions", Culture\& Psychology, 6(1): 5-39.

[47] Rosaldo, Michelle. (1984) "Toward and anthropology of self and feeling." In Richard Shweder. and Robert LeVine (eds.), Culture Theory: essays on mind, self, and emotion (pp. 137-157). Cambridge: Cambridge University Press.

[48] Schaeffer, John (1990). Sensus Communis: Vico, Rhetoric and the Limits of Relativism. Durham: Duke University Press.

[49] Seeman, Melvin. (1959). "On the Meaning of Alienation", American Sociological Review, 24: 783-791.

[50] Seeman, Melvin. (1967). "On the Personal Consequences 
ofAlienation in Work", American Sociological Review, 32: 273-285.

[51] Shilling, Chris. (2002). "The Two Traditions in the Sociology of Emotions." In Jack Barbalet (ed.), Emotions and Sociology (pp. 10-32). Oxford: Blackwell.

[52] Shweder, Richard A. (1994). "You're not sick, you're just in love": Emotion as an interpretive system. In Paul Ekman and Richard J. Davidson (eds.) The Nature of Emotion: Fundamental Questions (pp. 32-44). New York: Oxford University Press.

[53] Summers-Effker, Erika. (2002). "The Micro Potential for Social Change: Emotion, Consciousness, and Social Movement Formation", Sociological Theory, 20(1): 41-60.

[54] Thoits, Peggy A. (1990). "Emotional Deviance: Research Agenda." In Theodore D. Kemper (ed.), Research Agenda s in the Sociology of Emotions (pp. 180-206). Albany: State University of New York Press.

[55] Vygotsky, Lev S. (1987). The Collected Works of L.S.
Vygotsky: Volume I. Problems of General Psychology. New York: Plenum.

[56] Weiler, Katherine. (1991). Freire and a Feminist Pedagogy of Difference. Harvard Educational Review, 61(4): 449-474.

[57] Weiler, Katherine. (1996). "Myth of Paulo Freire", Educational Theory, 46(3): 353-371.Wentworth, William M. and Ryan, John. (1992). "Balancing Body, Mind and Culture: The Place of Emotion in Social Life. "In David D. Franks (ed.), Social Perspectives on Emotions (pp. 25-46). Greenwich, CT: JAI Press.

[58] Williams, Raymond. (1977). Marxism and Literature. Oxford: Oxford University Press.

[59] Williams, Raymond. (1981). Culture. London: Fontana.

[60] Willis, Paul. (1977). Learning to Labor: How Working class Kids Get Working Class Jobs. New York: Columbia University Press.

[61] Woods, Peter. (1979). The Divided School. London: RKP. 